\title{
A Review of Doing a Master's Dissertation in TESOL and Applied Linguistics
}

Xu Yang ${ }^{1 *}$ and Honggang Liu ${ }^{2}$

${ }^{12}$ Department of English, School of Foreign Languages, Northeast Normal University, China

Corresponding Author: Xu Yang, E-mail: yangx937@ nenu.edu.cn

\section{ARTICLE INFORMATION}

Received: September 06, 2020

Accepted: October 12, 2020

Volume: 2

Issue: 4

DOI: $10.32996 /$ jeltal.2020.2.4.1

\section{ABSTRACT}

This review begins with a brief introduction of the organization and main content of the book under review-Doing a Master's Dissertation in TESOL and Applied Linguistics, followed by the analysis of the contributions and limitations. On the whole, this book is practical and valuable for Master's students and supervisors who are looking for a holistic guide in TESOL and Applied Linguistics.

\section{KEYWORDS}

Project design; research

procedure; dissertation writing

and submission; applied

linguistics; TESOL

Dissertation writing is a challenging undertaking for MA students who do not have prior experience of such a task, demanding more involvement and skills than undergraduate essays (Wagener, 2018). Therefore, effective guidance is needed to direct the research and writing process. As the title suggests, this book specifically targets Master's students in TESOL and applied linguistics, offering guidance for "Master's students tackling research and research writing for the first time" (p. i). It addresses a comprehensive range of topics, including research design and execution, dissertation writing, the examination of dissertations, as well as issues beyond the dissertation.

This book has 16 chapters. The first is an introductory chapter, and the final one provides facilitative resources for dissertation writing. The remaining 14 chapters are divided into four parts: Part I, Project Design (Chapters 2 to 6); Part II, Data Collection and Analysis (Chapters 7 and 8); Part III, Dissertation Writing (Chapters 9 to 13); and Part IV, Dissertation Submission (Chapters 14 and 15). Drawing on Lindy Woodrow's rich experience of supervising a number of Master's students, at the end of these 14 chapters there are frequently asked questions along with answers, and common mistakes as well as suggestions for further reading.

The introductory chapter opens with the definition and writing purposes of the dissertation. After offering guidance for using the book and an introduction of the content, the author provides readers with suggestions to manage the dissertation writing process in terms of time and writing psychology, such as planning academic tasks on a calendar and keeping a research diary.

Part I comprises five chapters looking at the design stage of a research project. Chapter 2 examines the selection of a researchable topic. After proposing six methods of topic selection, this chapter discusses how to narrow a broad topic into a specific title for the dissertation. Chapter 3 focuses on the process of reviewing the literature, which is divided into 3 stages: broad review, source selection, and reading. This chapter begins by exploring what to review, and the focus then moves on to how to review. Chapter 4 gives an overview of methodologies and methods commonly used at the initial stages of project design, addressing pertinent issues in terms of methodological approach, research design, and the methods used for data collection, analysis, and sampling. Chapter 5 centers on the process of developing a dissertation proposal. After examining

K C AL-KINDI CENTER R D FOR RESEARCH AND D DEVELOPMENT Your gateway to world-class research
Published by Al-KindiCenter for Research and Development. Copyright (c) the author(s). This is an open access article under CC BY license (https://creativecommons.org/licenses/by/4.0/) 
the purpose of writing a research proposal, the commonly required components are briefly discussed. Finally, in this section, Chapter 6 looks at Master's dissertation supervision, from the allocation of a supervisor to the process of supervision. The performance of students in terms of their dissertation writing depends heavily on the supervision process (Wagener, 2018), and in this respect, strategies for coping with common problems occurring in dissertation supervision are provided throughout this chapter.

Part II addresses the research procedure that is part of a Master's project-that is, data collection and data analysis. Students, especially those new to research, will find these two chapters illuminating because of the inclusion of a great number of tables which illustrate the research procedure. Focusing on data collection, Chapter 7 first presents strategies for how to recruit participants, and then discusses the two most commonly used methods of data collection in Master's projects, namely questionnaires and interviews, ending with some problems that are frequently encountered in data collection procedures. In Chapter 8 distinctions are made between quantitative and qualitative analyses, and the stages of analysis are outlined. Suggestions for conducting data analysis are provided, with particular reference to keeping a research diary.

Part III consists of 5 chapters, addressing issues that may be encountered while writing a dissertation. Chapter 9 centers on the overall process of dissertation writing, and the remaining four chapters look at writing specific parts of the dissertation. Chapter 9 provides general writing guidelines, discussing the organization and writing requirements of a Master's dissertation. Features related to academic styles are then explored in a section, with four subsections focusing on a discrete facet of academic writing.

Chapters 10 to 12 employ the same approach, with the writing of discrete parts of the dissertation being discussed from the perspectives of purpose, organization, content, and language. Examples drawn from authentic Master's dissertations in TESOL and applied linguistics are presented in these chapters. Chapter 13 discusses the purposes and typical structures of the introduction and conclusion chapters, followed by a section on the reference list which provides rules and advice for referencing.

Part IV consists of two chapters. Chapter 14 focuses on putting the finishing touches to the dissertation, dealing with writing the final sections of the dissertation before submission. This chapter includes a section on editing and proofreading, in which the author addresses when, who, and how to edit and proofread, with some strategies being offered. Chapter 15 first describes the examination of the dissertation and the process of participating in a viva, with the focus then moving on to consider possible options after submission and examination, such as resubmission.

The concluding chapter (Chapter 16) is especially useful for dissertation writing in that it provides a whole variety of lists and links to facilitative resources. This chapter includes an example of a research proposal with annotation, followed by a section containing examples of some Master's dissertation abstracts adopting different study designs.

This is a practice-oriented book which should enable MA students to write high-quality dissertations, with the inclusion of practice tasks in each chapter and a large number of figures and tables (a total of 151 graphs) which make it easy for the reader to understand the main points discussed. In addition, templates are presented in several chapters which can be used or modified in the writing process-for instance, in Chapter 9 a template for a writing diary is offered to help writers overcome procrastination.

Although this book has its strengths as discussed above, readers may question the necessity of adding it to the literature, given that there are already a great many guides and handbooks related to dissertation and thesis writing. Some of the existing guides are general, applicable to all disciplines and research degrees, while others target a particular field of study or degree. We would argue that the contribution of Doing a Master's Dissertation in TESOL and Applied Linguistics to the literature lies in two aspects: the focused audience, and the holistic topics.

First, as the author describes, this book is "tailormade for MA students in TESOL or applied linguistics" (p. i). Substantial attention in similar handbooks has been given to doctoral theses, while Master's dissertations have received limited attention in comparison (Silinda, 2019). In terms of Master's dissertations, Samraj (2008) argues that the organization and set of texts for Master's dissertations vary across disciplines, and there is therefore a need for guides targeting specific disciplines. Few of the existing guides specially target dissertations in TESOL or applied linguistics, especially Master's dissertations. Against this backdrop, this book is a timely and welcome addition to the literature.

The second contribution of this book lies in the range of topics it covers. A great many guides discuss how to design and execute research as well as how to write a thesis or dissertation, but few of them address issues relevant to the examination 
of dissertations and beyond. Filling this gap, the book covers a holistic range of topics, including research design, dissertation writing, and examinations, as well as options after examination such as resubmission or applying for a higher research degree.

However, because the book is limited by space, a thorough discussion of these topics is not possible. Some of the topics in this book are briefly discussed in a way that makes it suitable for first-time writers to grasp the general process of dissertation writing-which, in our opinion, is a feature of this book rather than a shortcoming. However, it makes the book perhaps less useful to readers who require detailed and thorough information on a specific topic. To mitigate this, links to useful web resources are included in many of the chapters, and Chapter 16 provides a lot of links and lists of resources so that the interested reader can find more in-depth reading.

Despite the contributions of this book, there is one minor flaw. The whole volume is well-organized, except for an inappropriate division of sections in some chapters. For instance, in Chapter 15 there are 3 consecutive subsections entitled "disseminating knowledge", "giving a conference presentation", and "publishing a journal article". In terms of content, the latter two should belong to the first subsection, "disseminating knowledge", rather than being presented in parallel. However, this does not detract from the fact that this book is an essential and welcome addition to the dissertation writing literature.

All in all, this book is worthy of recommendation, and it will be of great value to Master's students tackling research and dissertation writing, especially those new to dissertation writing. We think this book will be an "encyclopedia" which will solve most of the problems that Master's students may encounter in the dissertation writing process. In addition to Master's students, however, this book will also be of use to supervisors and program directors, as they will be able to deploy the examples and strategies in this book to guide their student writers, or recommend this book to their students. It could be used either as a reference guide for independent learning or as a textbook in class.

\section{Acknowledgement}

This review was supported by the Project of Discipline Innovation and Advancement (PODIA) - Foreign Language Education Studies at Beijing Foreign Studies University (Grant number: 2020SYLZDXM011).

\section{About the Authors}

Xu Yang is a Master's student in applied linguistics in the Department of English, School of Foreign Languages, Northeast Normal University (NENU), China. Her research interest lies in L2 motivation.

Honggang Liu works as full professor of applied linguistics in the Department of English, School of Foreign Languages, Northeast Normal University (NENU), China. His research focuses on applied linguistics and language education with more intensive attention on the areas of the psychology for language learning and teaching (motivation, learning strategy, emotion, agency, etc.), social class and foreign language learning, and language teacher education.

\section{References}

[1] Samraj, B. (2008). A discourse analysis of Master's theses across disciplines with a focus on introductions. Journal of English for Academic Purposes, 7(1), 55-67.

[2] Silinda, F. T. (2019). A transactional approach to predicting stress experienced when writing dissertations. South African Journal of Psychology, 49(3), 417-429.

[3] Wagener, B. (2018). The importance of affects, self-regulation and relationships in the writing of a Master's thesis. Teaching in Higher Education, 23(2), 227-242.

[4] Woodrow, L. (2020). Doing a Master's dissertation in TESOL and applied linguistics. Abingdon, Oxon; New York: Routledge. 